\title{
The Inhibition Effect of Potassium Iodide on the Corrosion of Pure Iron in Sulphuric Acid
}

\author{
Tarik Attar, ${ }^{1,2}$ Lahcène Larabi, $^{1}$ and Yahia Harek ${ }^{1}$ \\ ${ }^{1}$ Laboratory of Analytical Chemistry and Electrochemistry, Department of Chemistry, Faculty of Sciences, P.O. Box 119, \\ University Abou-Bekr Belkaïd, 13000 Tlemcen, Algeria \\ ${ }^{2}$ University Center of Nâ̂ma, BP 66, 45000 Naâma, Algeria \\ Correspondence should be addressed to Tarik Attar; t_attar@mail.univ-tlemcen.dz
}

Received 29 June 2014; Accepted 8 September 2014; Published 24 September 2014

Academic Editor: Armando Zarrelli

Copyright (C) 2014 Tarik Attar et al. This is an open access article distributed under the Creative Commons Attribution License, which permits unrestricted use, distribution, and reproduction in any medium, provided the original work is properly cited.

\begin{abstract}
The use of inorganic inhibitors as an alternative to organic compounds is based on the possibility of degradation of organic compounds with time and temperature. The inhibition effect of potassium iodide on the corrosion of pure iron in $0.5 \mathrm{M} \mathrm{H}_{2} \mathrm{SO}_{4}$ has been studied by weight loss. It has been observed from the results that the inhibition efficiency (IE\%) of KI increases from $82.17 \%$ to $97.51 \%$ with the increase in inhibitor concentration from $1 \cdot 10^{-4}$ to $2 \cdot 10^{-3} \mathrm{M}$. The apparent activation energy $\left(E_{a}\right)$ and the equilibrium constant of adsorption $\left(K_{\mathrm{ads}}\right)$ were calculated. The adsorption of the inhibitor on the pure iron surface is in agreement with Langmuir adsorption isotherm.
\end{abstract}

\section{Introduction}

Corrosion is the deterioration of materials by chemical interaction with their environment [1]. Corrosion can cause disastrous damage to metal and alloy structures causing economic consequences in terms of repair, replacement, product losses, safety, and environmental pollution [2]. Several protective measures are taken to control and prevent corrosion. One of these is the use of corrosion inhibitors, which are usually chemical substances; when added in a small concentration to a corrosive medium, they reduce effectively the corrosion of the metal and/or alloy [3,4]. The use of corrosion inhibitors constitutes one of the most economical ways to mitigate the corrosion rate [5]. The corrosion and corrosion protection of iron in corrosive environments have attracted the attention of many investigators [6-8]. Iron plays a central role as one of the most widely used materials in our daily life because of its so many applications [9]. The inhibition efficiency depends on the parameters of the corrosive system $[\mathrm{pH}$, temperature, duration, metal composition, etc.] and on the nature of the inhibitor [10]. Sulfuric acid is one of the most aggressive acids for iron and its alloys and is often used during cleaning, pickling, descaling, acidizing, and so forth [11, 12]. The inhibitor molecules get bonded to the metal surface by chemisorption, physisorption, or complexation with the polar groups acting as the reactive centers in the molecules [13].

\section{Experimental}

2.1. Materials. The weight loss experiments were conducted in a $150 \mathrm{~mL}$ beaker; the electrolyte volume is $100 \mathrm{~mL}$. Julabo thermostat brand keeps the electrolyte at the desired temperature $\left( \pm 0.1^{\circ} \mathrm{C}\right)$.

The test pieces were mechanically polished with emery paper (a coarse paper was used initially and then progressively finer grades were employed, 400 to 1200 grade). The specimens were weighed by electronic digital analytical balance with five decimal accuracies before and after exposure.

2.2. Electrolyte. The corrosive solution, $0.5 \mathrm{M} \mathrm{H}_{2} \mathrm{SO}_{4}$, was obtained by dilution of analytical grade $98 \%$ sulphuric acid with bidistilled water. The concentration range of inhibitor employed was $1 \cdot 10^{-4}$ to $2 \cdot 10^{-3} \mathrm{M}$ in the sulphuric acid.

2.3. Weight Loss Method. The test pieces were washed with bidistilled water, degreased with acetone, washed again 
with bidistilled water, dried between two filter papers, and weighed. After specified periods of time, 3 test pieces were taken out of the test solution, rinsed with bidistilled water, dried as before, and weighed again. The average weight loss at a certain time for each set of three samples was taken. The weight loss experiments were performed after an exposure of $2 \mathrm{~h}$. The inhibition efficiency of potassium iodide was expressed in terms of percentage inhibition, calculated using

$$
\operatorname{IE}(\%)=\left(\frac{w_{\text {corr }}-w_{\text {inh }}}{w_{\text {corr }}}\right) \times 100,
$$

where $W_{\text {corr }}$ is the corrosion rate of blank sulfuric acid and $W_{\text {inh }}$ is the corrosion rate after adding inhibitor.

The corrosion rate $(W)$ was calculated from the following equation:

$$
w=\left(\frac{m_{1}-m_{2}}{S \cdot t}\right)
$$

where $m_{1}$ is the mass of the specimen before corrosion, $m_{2}$ is the mass of the specimen after corrosion, $S$ is the total area of the specimen, $t$ is the corrosion time, and $W$ is the corrosion rate.

The degree of surface coverage $(\Theta)$ was calculated using the following equation:

$$
\theta=1-\frac{w_{\text {inh }}}{w_{\text {corr }}} .
$$

\section{Results and Discussion}

3.1. Effect of Inhibitor Concentration. The values of percentage inhibition efficiency (IE\%) and corrosion rate $(w)$ at different concentrations of $\mathrm{KI}$ at $303 \mathrm{~K}$ are summarized in Table 1. Figure 1 shows the results obtained from weight loss measurements for pure iron in $0.5 \mathrm{M} \mathrm{H}_{2} \mathrm{SO}_{4}$ solutions in the absence and presence of different concentrations of KI. It has been observed from the results that the IE\% of KI increases from $82.17 \%$ to $97.51 \%$ with the increase in inhibitor concentration from $1 \cdot 10^{-4}$ to $2 \cdot 10^{-3} \mathrm{M}$. The optimum concentration of this effect is $2 \cdot 10^{-3} \mathrm{M}$.

Figure 2 shows that the corrosion rate decreases with increasing concentration of inhibitor, which explains the effect of protection against the corrosion by the type of inhibitor selected.

3.2. Effect of Immersion Time. The weight loss measurements were performed in $0.5 \mathrm{M} \mathrm{H}_{2} \mathrm{SO}_{4}$ in absence and presence of $\mathrm{KI}$ at $2 \cdot 10^{-3} \mathrm{M}$ concentration for $30 \mathrm{~min}$ to $6 \mathrm{~h}$ immersion time at temperature of $303 \mathrm{~K}$. Inhibition efficiencies were plotted against immersion time as seen in Figure 3. This figure shows that inhibition efficiency of the potassium iodide was increased with increasing immersion time. The increase in inhibition efficiency up to $2 \mathrm{~h}$ reflects the inorganic inhibitor adsorption of constituents on the pure iron surface. This result indicates a stabilization of the inhibition rate from 2 hours of immersion. According to this study, it was found that $\mathrm{KI}$ is a very effective inhibitor for pure iron in $\mathrm{H}_{2} \mathrm{SO}_{4} 0.5 \mathrm{M}$ because after an immersion time of half an hour the power of protection already achieved $94.91 \%$.

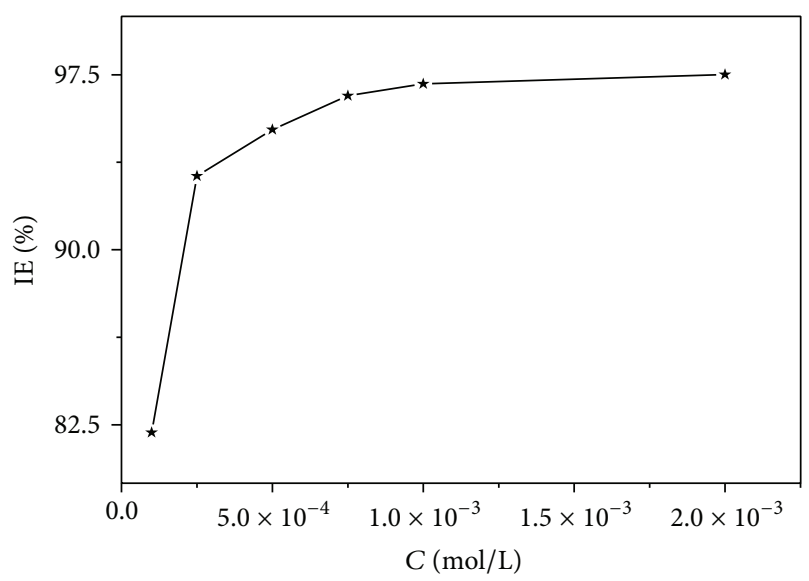

FIGURE 1: Variation of inhibition efficiency with KI concentration.

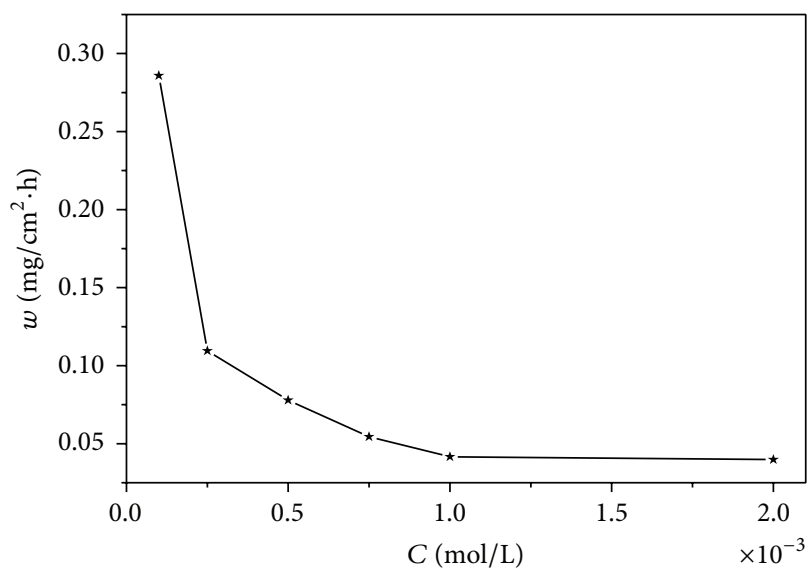

FIGURE 2: Plot of corrosion rate versus inhibitor concentration for pure iron test specimens after $2 \mathrm{hrs}$ of exposure.

3.3. Effect of Temperature. In order to study the effect of temperature on the inhibition efficiencies of potassium iodide, weight loss measurements were carried out in the temperature range $293-323 \mathrm{~K}$ in absence and presence of inhibitor at optimum concentration during 2 hours of immersion. Table 2 shows the effect of temperature on the corrosion rate of pure iron in absence and presence of inhibitor. It is evident from this table that inhibition efficiency increases with increasing temperature.

The apparent activation energy $E_{a}$ for pure iron corrosion in $0.5 \mathrm{M} \mathrm{H}_{2} \mathrm{SO}_{4}$ in the absence and presence of inhibitors was evaluated from Arrhenius equation [14]:

$$
\ln (w)=-\frac{E_{a}}{R T}+A
$$

where $w$ is the corrosion rate determined from gravimetric measurements, $A$ is the Arrhenius frequency factor, $R$ is the molar gas constant, and $T$ is the absolute temperature.

The plots of $\ln (w)$ against $1 / T$ were linear, as shown in (Figure 4); $E_{a}$ values were obtained from the slope and are as presented in Table 3. 
TABLE 1: Corrosion parameters for pure iron in aqueous solution of $0.5 \mathrm{M} \mathrm{H}_{2} \mathrm{SO}_{4}$ in presence and absence of different concentrations of $\mathrm{KI}$ at $303 \mathrm{~K}$ for $2 \mathrm{~h}$.

\begin{tabular}{lccc}
\hline & $C(\mathrm{~mol} / \mathrm{L})$ & $w\left(\mathrm{mg} \cdot \mathrm{cm}^{-2} \cdot \mathrm{h}^{-1}\right)$ & IE (\%) \\
\hline $\mathrm{H}_{2} \mathrm{SO}_{4}$ & 0.5 & 1.60383 & - \\
\hline & $1 \cdot 10^{-4}$ & 0.28593 & 82.17 \\
& $2.5 \cdot 10^{-4}$ & 0.10956 & 93.16 \\
$\mathrm{KI}$ & $5 \cdot 10^{-4}$ & 0.07787 & 95.15 \\
& $7.5 \cdot 10^{-4}$ & 0.05445 & 96.60 \\
& $1 \cdot 10^{-3}$ & 0.04169 & 97.11 \\
& $2 \cdot 10^{-3}$ & 0.03986 & 97.51 \\
\hline
\end{tabular}

TABLE 2: Effect of temperature on pure iron in the presence and absence of KI, at $2 \mathrm{~h}$.

\begin{tabular}{lccc}
\hline$T(\mathrm{~K})$ & $w_{0}\left(\mathrm{mg} / \mathrm{cm}^{2} \cdot \mathrm{h}^{1}\right)$ & $w_{\text {inh }}\left(\mathrm{mg} / \mathrm{cm}^{2} \cdot \mathrm{h}^{1}\right)$ & IE $(\%)$ \\
\hline 293 & 0.15107 & 0.00622 & 95.88 \\
303 & 0.34152 & 0.01329 & 96.10 \\
313 & 1.32256 & 0.05035 & 96.19 \\
323 & 3.43109 & 0.11280 & 96.71 \\
\hline
\end{tabular}

TABLE 3: The values of activation parameters for pure iron in $0.5 \mathrm{M} \mathrm{H}_{2} \mathrm{SO}_{4}$ in the absence and the presence of inhibitor of $2 \cdot 10^{-3} \mathrm{M}$ concentration at $2 \mathrm{~h}$.

\begin{tabular}{lccc}
\hline $\begin{array}{l}\text { Concentration } \\
\text { of inhibitor }(\mathrm{M})\end{array}$ & $\begin{array}{c}E_{a} \\
(\mathrm{~kJ} / \mathrm{mol})\end{array}$ & $\begin{array}{c}\Delta H_{a} \\
(\mathrm{~kJ} / \mathrm{mol})\end{array}$ & $\begin{array}{c}E_{a}-\Delta H_{a} \\
(\mathrm{~kJ} / \mathrm{mol})\end{array}$ \\
\hline $0.5 \mathrm{H}_{2} \mathrm{SO}_{4}$ & 84.32 & 81.65 & 2.67 \\
$2 \cdot 10^{-3} \mathrm{KI}$ & 78.89 & 76.22 & 2.67 \\
\hline
\end{tabular}

A plot of $\ln (w / T)$ versus $1 / T$ gave a straight line (Figure 5) with a slope of $-\left(\Delta H_{a} / R\right)$ from which the value of $\Delta H_{a}$ was calculated and listed in Table 3.

The $E_{a}$ values in the presence of inhibitor are lower than in the absence of inhibitor indicating that the inhibition efficiency increases with increases in temperature. The positive sign of enthalpy of activation reflects the endothermic nature of the steel dissolution process.

3.4. Adsorption Isotherm. Adsorption isotherms provide information about the interaction of the adsorbed molecules with the electrode surface [15]. The adsorption of the inhibitors can be described by two main types of interaction: physical adsorption and chemisorptions [16, 17]. These are influenced by the chemical structure of the inhibitor, the type of the electrolyte, $\mathrm{pH}$, the charge and nature of the metal, and temperature [18]. The phenomenon of interaction between the metal surface and the inhibitor can be better understood in terms of adsorption isotherm. The plots of $C_{\text {inh }} / \theta$ against $C$ (Figure 6) yield a straight line with approximately unit slope, indicating that the inhibitor under study obeys Langmuir adsorption isotherm. According to this isotherm, $\theta$ is related to $C_{\text {inh }}$ by [19]:

$$
\frac{C_{\text {inh }}}{\theta}=\frac{1}{K_{\text {ads }}}+C_{\text {inh }} .
$$

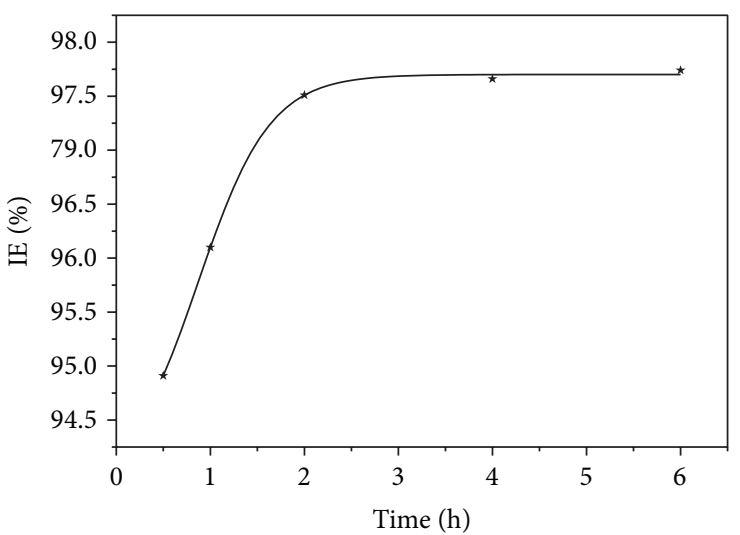

FIGURE 3: Variation of inhibition efficiency of KI with immersion time.

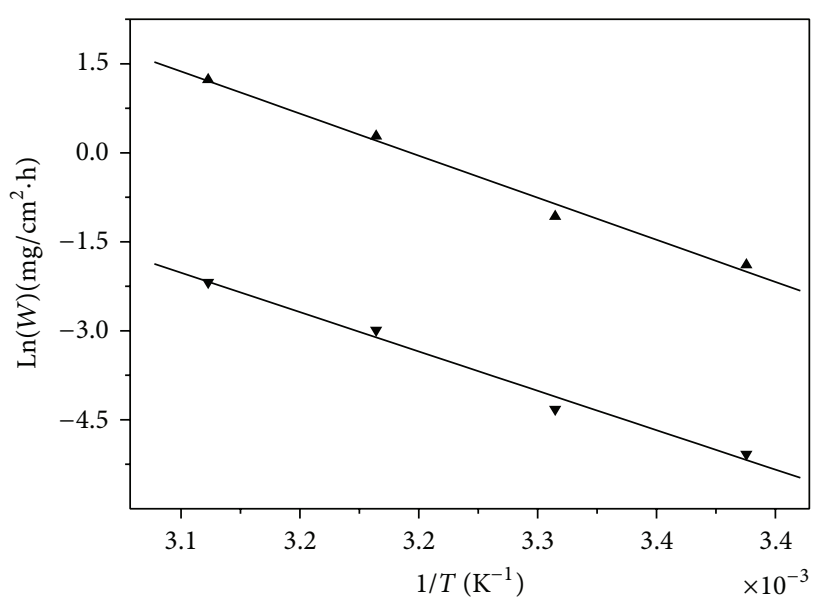

- $\mathrm{H}_{2} \mathrm{SO}_{4} 0.5 \mathrm{M}$

$\checkmark \mathrm{KI} 2.10^{-3} \mathrm{M}$

FIGURE 4: Adsorption isotherm plots for $\ln w$ versus $1 / T$.

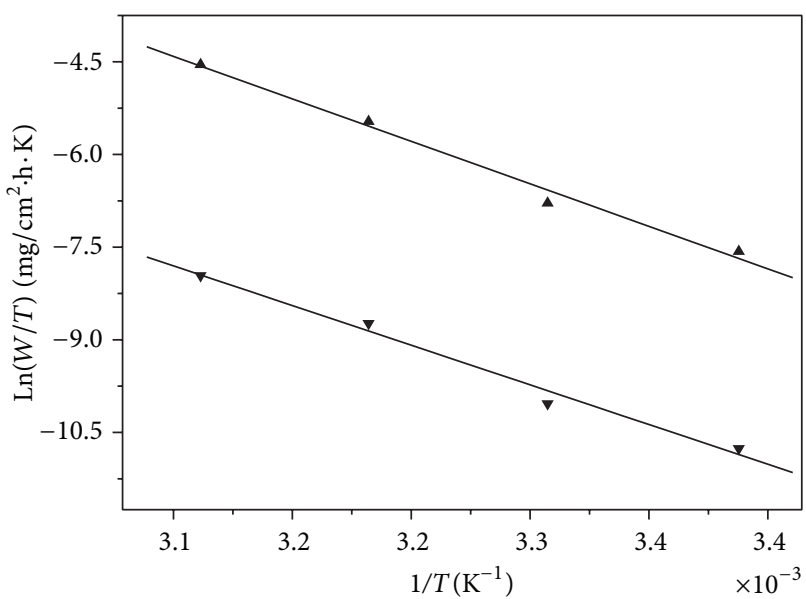

$\Delta \mathrm{H}_{2} \mathrm{SO}_{4} 0.5 \mathrm{M}$

- $\mathrm{KI} 2.10^{-3} \mathrm{M}$

FIGURE 5: Adsorption isotherm plots for $\ln (w / T)$ versus $1 / T$. 


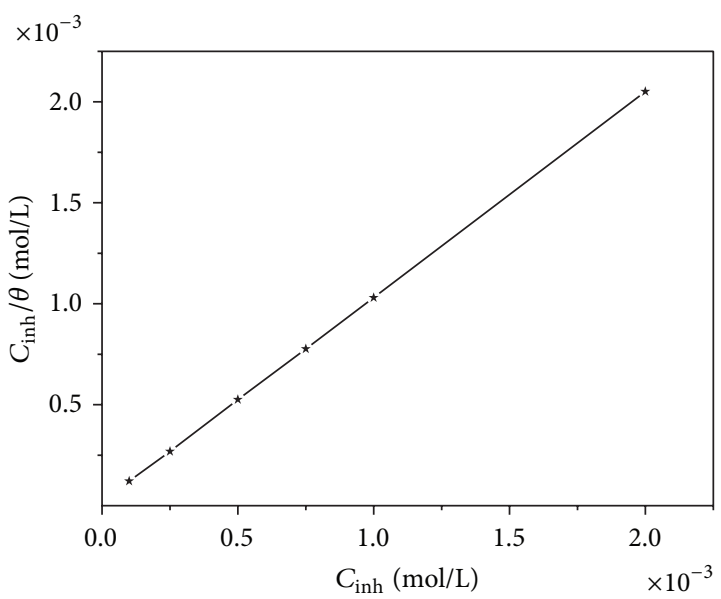

Figure 6: Relationship between $\left(C_{\text {inh }} / \theta\right)$ and inhibitor concentration $C_{\text {inh }}$.

The $K_{\text {ads }}$ values can be calculated from the intercept lines on the $C_{\text {inh }} / \theta$-axis. This is related to the standard free energy of adsorption $\left(\Delta G_{\mathrm{ads}}\right)$ with the following equation [20]:

$$
K_{\mathrm{ads}}=\left(\frac{1}{55.5}\right) \exp \left(-\frac{\Delta G_{\mathrm{ads}}}{R T}\right),
$$

where

$$
\Delta G_{\mathrm{ads}}=-R T \ln \left(55.5 K_{\mathrm{ads}}\right),
$$

where $R$ is the gas constant and $T$ is the absolute temperature. The constant value of 55.5 is the concentration of water in solution in $\mathrm{mol} / \mathrm{dm} 3$ [21].

The intercept permits the calculation of the equilibrium constant $K_{\mathrm{ads}}$ which is $6.17 \times 10^{4} \mathrm{~L} / \mathrm{mol}$, respectively. The value of $K_{\mathrm{ads}}$ which indicates the binding power of the inhibitor to the pure iron surface leads to calculation of adsorption energy. Value of $\Delta G_{\text {ads }}$ is $-37.55 \mathrm{~kJ} / \mathrm{mol}$, respectively. The negative values of $\Delta G_{\text {ads }}$ showed that the adsorption of inhibitor molecules on the metal surface is spontaneous [22].

Generally, the standard free energy values of $-20 \mathrm{~kJ} / \mathrm{mol}$ or less negative are associated with an electrostatic interaction between charged molecules and charged metal surface (physical adsorption); those of $-40 \mathrm{~kJ} / \mathrm{mol}$ or more negative involves charge sharing or transfer from the inhibitor molecules to the metal surface to form a co-ordinate covalent bond (chemical adsorption).

Note that our measures were carried out without inert atmosphere. In $1 \mathrm{M} \mathrm{H}^{+}$, the iodide ion becomes hydrogen iodide which reacts with oxygen to form molecule iodide $\mathrm{I}_{2}$. The formed molecule could be adsorbed onto iron and occupying the surface, it strikes the adsorption of iodide. At the end, a lower efficiency of adsorption of iodide was obtained but the inhibition efficiency of the studied inhibitor $\mathrm{KI}$ increases due to adsorption of $\mathrm{I}_{2}$.

Otherwise the value of $\Delta G_{\text {ads }}(-37.55 \mathrm{~kJ} / \mathrm{mol})$ near to $-40 \mathrm{~kJ} / \mathrm{mol}$ indicates that, in our case, the adsorption is neither typical chemisorption nor typical physisorption but it is a complex mixed type. That is, the adsorption inhibitor molecule on the iron surface in the present study involves both chemisorption (of $\mathrm{I}_{2}$ ) and physisorption (of $\mathrm{I}^{-}$) but chemisorption is the predominant mode of adsorption. This assumption is supported by the data obtained from temperature dependence of inhibition process, reported in Tables 2 and 3, which show that the inhibition efficiency of the studied compound as inhibitor increases with increase in temperature and that the value of $E_{a}$ in absence of the inhibitor is lower than that in its presence [23]. On the other hand it is known that the iron surface acquires positive charge in $\mathrm{H}_{2} \mathrm{SO}_{4} 0.5 \mathrm{M}$ [24], while iodide ion is negatively charged, as a result the physisorption (electrostatic attraction) of the iodide ion occurs onto iron surface.

\section{Conclusion}

On the basis of the experimental results obtained in the present study, the following conclusions can be drawn.

(1) Potassium iodide is a good inhibitor for pure iron corrosion in $0.5 \mathrm{M} \mathrm{H}_{2} \mathrm{SO}_{4}$ solution. The inhibition efficiency increases with increased KI concentration to attain a maximum value of $97.51 \%$ at $2 \cdot 10^{-3} \mathrm{M}$.

(2) The adsorption of KI on pure iron obeyed Langmuir adsorption isotherm.

(3) At higher experimental temperature, inhibitor molecules are adsorbed into the metal surface.

(4) The negative value of $\Delta G_{\text {ads }}$ is a sign of spontaneous adsorption on the metal surface.

\section{Conflict of Interests}

The authors declare that there is no conflict of interests regarding the publication of this paper.

\section{References}

[1] B. Eker and E. Yuksel, "Solutions to corrosion caused by agricultural chemicals," Trakia Journal of Sciences, vol. 3, no. 7, pp. 1-6, 2005.

[2] N. Patni, S. Agarwal, and P. Shah, "Greener Approach towards Corrosion Inhibition," Chinese Journal of Engineering, vol. 2013, Article ID 784186, 10 pages, 2013.

[3] T. H. Ibrahim and M. A. Zour, "Corrosion inhibition of mild steel using fig leaves extract in hydrochloric acid solution," International Journal of Electrochemical Science, vol. 6, no. 12, pp. 6442-6455, 2011.

[4] E.-S. M. Sherif, "Electrochemical and gravimetric study on the corrosion and corrosion inhibition of pure copper in sodium chloride solutions by two azole derivatives," International Journal of Electrochemical Science, vol. 7, no. 2, pp. 1482-1495, 2012.

[5] P. Rajeev, A. O. Surendranathan, and C. S. N. Murthy, "Corrosion mitigation of the oil well steels using organic inhibitors-a review," Journal of Materials and Environmental Science, vol. 3, no. 5, pp. 856-869, 2012. 
[6] E.-S. M. Sherif, "Corrosion and corrosion inhibition of pure iron in neutral chloride solutions by $1,1^{\prime}$ thiocarbonyldiimidazole," International Journal of Electrochemical Science, vol. 6, no. 8, pp. 3077-3092, 2011.

[7] H. Amar, A. Tounsi, A. Makayssi, A. Derja, J. Benzakour, and A. Outzourhit, "Corrosion inhibition of Armco iron by 2mercaptobenzimidazole in sodium chloride 3\% media," Corrosion Science, vol. 49, no. 7, pp. 2936-2945, 2007.

[8] E.-S. M. Sherif, R. M. Erasmus, and J. D. Comins, "In situ Raman spectroscopy and electrochemical techniques for studying corrosion and corrosion inhibition of iron in sodium chloride solutions," Electrochimica Acta, vol. 55, no. 11, pp. 3657-3663, 2010.

[9] E. S. M. Sherif, "Corrosion and corrosion inhibition of pure iron in neutral chloride solutions by $1,1^{\prime}$-thiocarbonyldiimidazole," International Journal of Electrochemical Science, vol. 6, pp. 30773092, 2011.

[10] R. T. Loto, C. A. Loto, and A. P. I. Popoola, "Corrosion inhibition of thiourea and thiadiazole derivatives: a review," Journal of Materials and Environmental Science, vol. 3, no. 5, pp. 885-894, 2012.

[11] T. Poornima, N. Jagannatha, and A. Nityananda Shetty, "Studies on corrosion of annealed and aged $18 \mathrm{Ni} 250$ grade maraging steel in sulphuric acid medium," Portugaliae Electrochimica Acta, vol. 28, no. 3, pp. 173-188, 2010.

[12] P. Kumar and A. N. Shetty, "Electrochemical investigation on the corrosion of $18 \% \mathrm{Ni} \mathrm{M} 250$ grade maraging steel under welded condition in sulfuric acid medium," Surface Engineering and Applied Electrochemistry, vol. 49, no. 3, pp. 253-260, 2013.

[13] I. Lukovits, E. Kálmán, and F. Zucchi, "Corrosion inhibitorscorrelation between electronic structure and efficiency," Corrosion, vol. 57, no. 1, pp. 3-8, 2001.

[14] M. A. Quraishi and S. Khan, “Thiadiazoles-A potential class of heterocyclic inhibitors for prevention of mild steel corrosion in hydrochloric acid solution," Indian Journal of Chemical Technology, vol. 12, no. 5, pp. 576-581, 2005.

[15] E. A. Noor and A. H. Al-Moubaraki, "Thermodynamic study of metal corrosion and inhibitor adsorption processes in mild steel/1-methyl- $4\left[4^{\prime}(-\mathrm{X})\right.$-styryl pyridinium iodides/hydrochloric acid systems," Materials Chemistry and Physics, vol. 110, no. 1, pp. 145-154, 2008.

[16] L. Larabi, O. Benali, and Y. Harek, "Corrosion inhibition of copper in $1 \mathrm{M} \mathrm{HNO}_{3}$ solution by $N$-phenyl oxalic dihydrazide and oxalic $N$-phenylhydrazide $N^{\prime}$-phenylthiosemicarbazide," Portugaliae Electrochimica Acta, vol. 24, no. 3, pp. 337-346, 2006.

[17] L. Larabi, Y. Harek, M. Traisnel, and A. Mansri, "Synergistic influence of poly(4-vinylpyridine) and potassium iodide on inhibition of corrosion of mild steel in $1 \mathrm{M} \mathrm{HCl,"} \mathrm{Journal} \mathrm{of}$ Applied Electrochemistry, vol. 34, no. 8, pp. 833-839, 2004.

[18] M. A. Ameer and A. M. Fekry, "Inhibition effect of newly synthesized heterocyclic organic molecules on corrosion of steel in alkaline medium containing chloride," International Journal of Hydrogen Energy, vol. 35, no. 20, pp. 11387-11396, 2010.

[19] M. Benabdellah, A. Aouniti, A. Dafali et al., "Investigation of the inhibitive effect of triphenyltin 2-thiophene carboxylate on corrosion of steel in $2 \mathrm{M} \mathrm{H}_{3} \mathrm{PO}_{4}$ solutions," Applied Surface Science, vol. 252, no. 23, pp. 8341-8347, 2006.

[20] A. M. Fekry and M. A. Ameer, "Corrosion inhibition of mild steel in acidic media using newly synthesized heterocyclic organic molecules," International Journal of Hydrogen Energy, vol. 35, no. 14, pp. 7641-7651, 2010.
[21] O. Olivares, N. V. Likhanova, B. Gómez et al., "Electrochemical and XPS studies of decylamides of $\alpha$-amino acids adsorption on carbon steel in acidic environment," Applied Surface Science, vol. 252, no. 8, pp. 2894-2909, 2006.

[22] A. Dabrowski, "Adsorption-from theory to practice," Advances in Colloid and Interface Science, vol. 93, no. 1-3, pp. 135-224, 2001.

[23] T. Szauer and A. Brandt, "On the role of fatty acid in adsorption and corrosion inhibition of iron by amine-fatty acid salts in acidic solution," Electrochimica Acta, vol. 26, no. 9, pp. 12571260, 1981.

[24] B. S. Prathibha, P. Kottees waram, and R. V. Bheema, "Study on the inhibition of mild steel corrosion by quaterwarey Ammonium compound in $\mathrm{H}_{2} \mathrm{SO}_{4}$ medium," Research Journal of Recent Sciences, vol. 2, no. 4, pp. 1-10, 2013. 

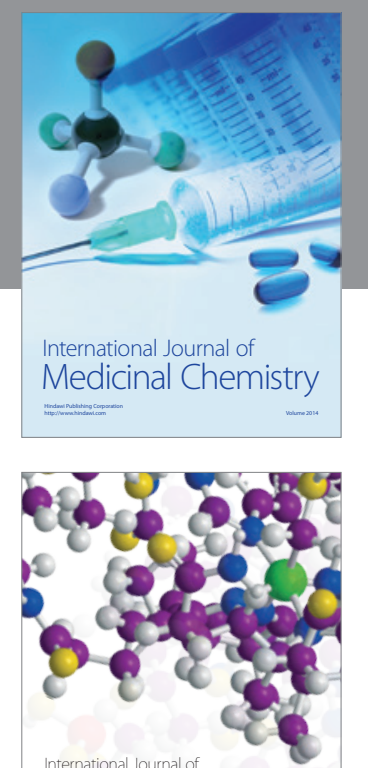

\section{Carbohydrate} Chemistry

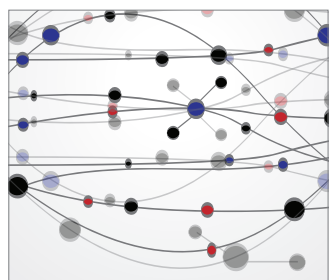

The Scientific World Journal
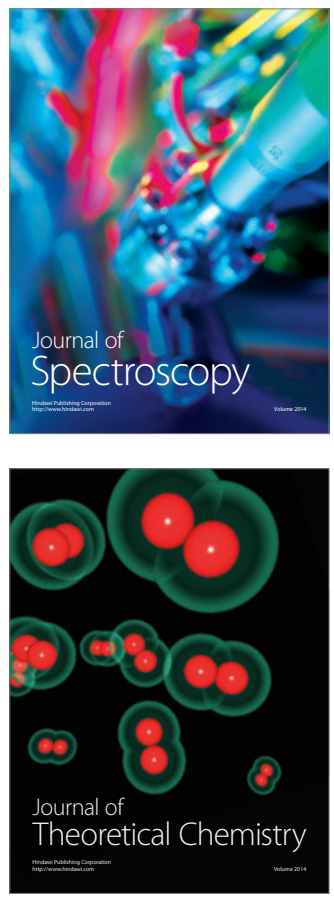
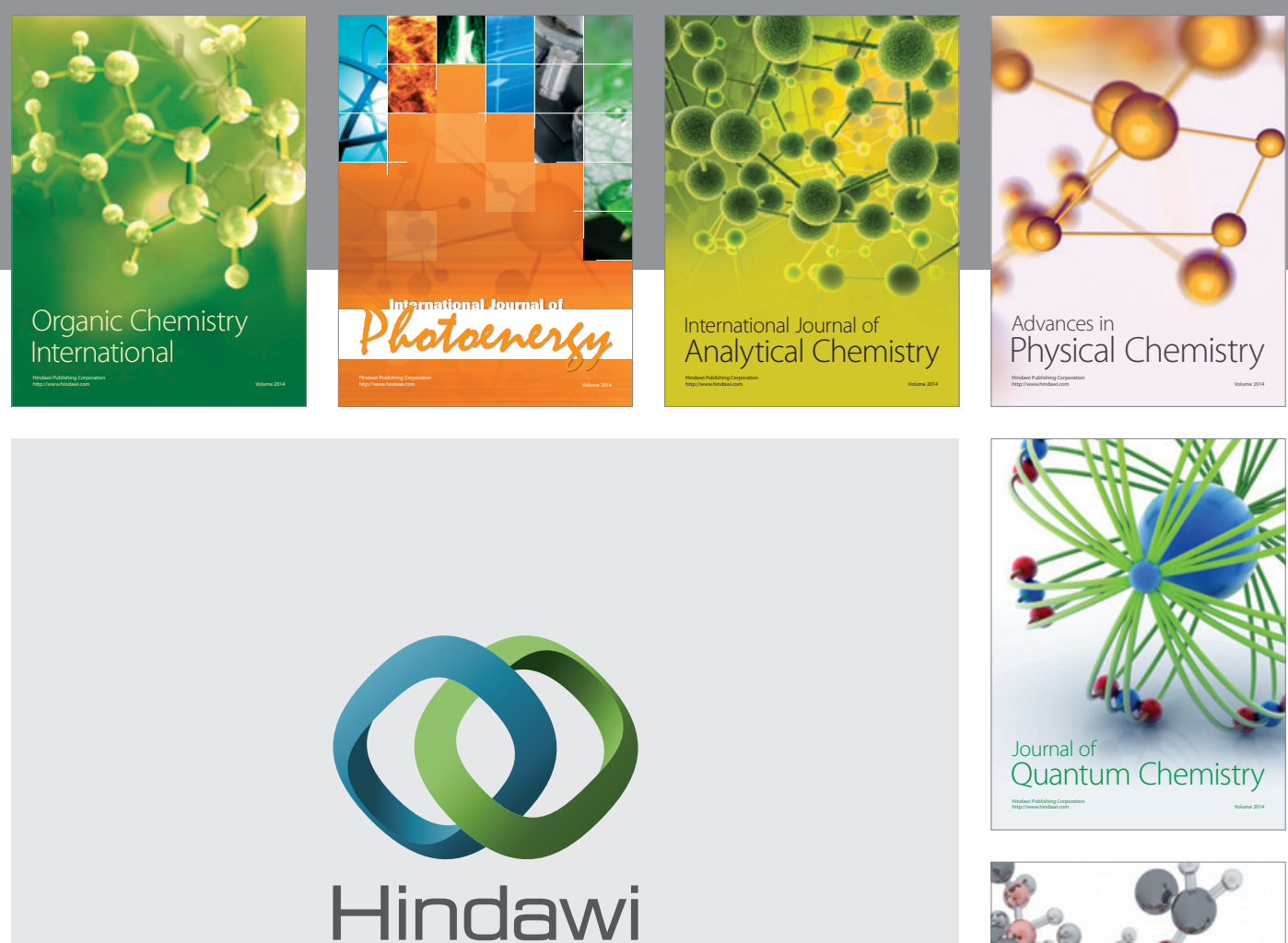

Submit your manuscripts at

http://www.hindawi.com

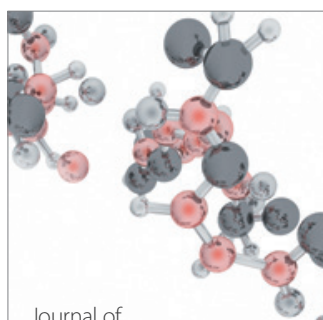

Analytical Methods

in Chemistry

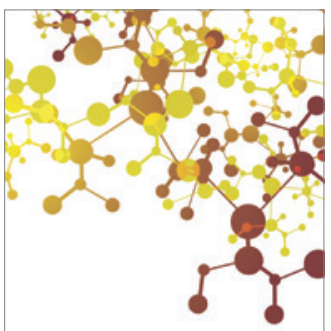

Journal of

Applied Chemistry

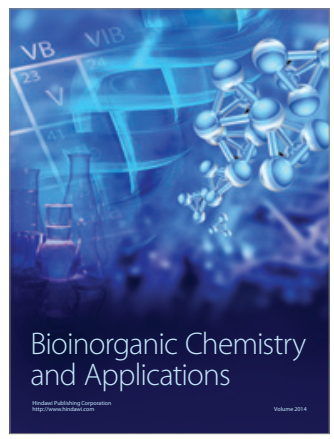

Inorganic Chemistry
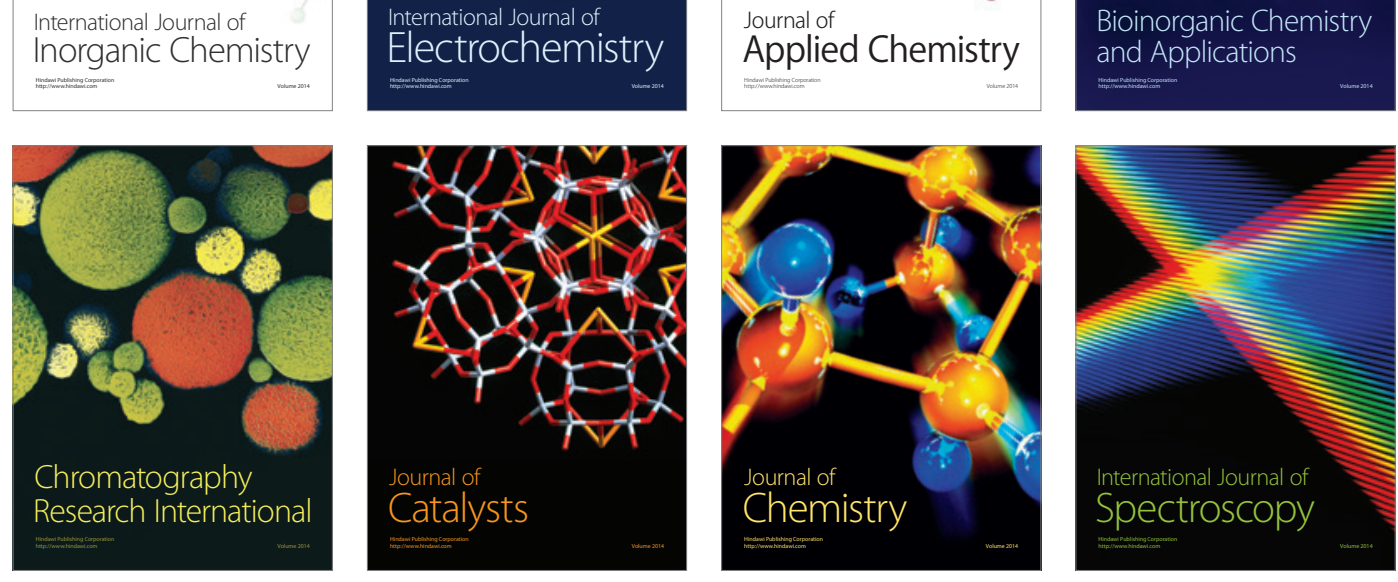